\title{
Patients' and Health Care Workers' Perception of Migraine Images on the Internet: Cross-sectional Survey Study
}

Bianca Raffaelli ${ }^{1}$, MD; Pia Kull ${ }^{1}$; Jasper Mecklenburg ${ }^{1}$, MD; Lucas Hendrik Overeem ${ }^{1}$, MSc; Elisabeth Storch ${ }^{1}$; Maria Terhart $^{1}$; Lars Neeb ${ }^{1}$, MD; Uwe Reuter ${ }^{1,2}$, MD, MBA

${ }^{1}$ Department of Neurology, Charité - Universitätsmedizin Berlin, Berlin, Germany

${ }^{2}$ Universitätsmedizin Greifswald, Greifswald, Germany

Corresponding Author:

Bianca Raffaelli, MD

Department of Neurology

Charité - Universitätsmedizin Berlin

Charitéplatz 1

Berlin, 10117

Germany

Phone: 4930450660888

Email: bianca.raffaelli@charite.de

\section{Abstract}

Background: The representation of migraine in the media is stereotypical. Standard images of migraine attacks display stylish young women holding their head in a pain pose. This representation may contribute to the social stigmatization of patients with migraine.

Objective: We aimed to analyze how patients with migraine and health care workers perceive online images of migraine.

Methods: The study consisted of an anonymous web-based survey of patients with migraine at the Headache Center of Charité - Universitätsmedizin Berlin (migraine group) and employees and students at our university (health care group). A total of 10 frequently used Adobe Stock photos of migraine attacks were presented to the participants. Each photo was rated on a scale of $0 \%$ to $100 \%$ based on how closely it resembled a realistic migraine attack (realism score). Patients with migraine also indicated how much each photo corresponded to their own experience of migraine as a percentage (representation score). We calculated the mean realism and representation scores for all photos and conducted further analyses using the categories male or female models, younger or older models, and unilateral or bilateral pain pose.

Results: A total of 367 patients with migraine and 331 health care employees and students completed the survey. In both groups, the mean realism score was $<50 \%$ (migraine group: $47.8 \%$, SD $18.3 \%$; health care group: $46.0 \%$, SD 16.2\%). Patients with migraine identified their own migraine experience in these photos to a lesser degree (mean representation score 44.4\%, SD 19.8\%; $P<.001$ when compared to the realism score). Patients and health care workers considered photos with male models to be more realistic than photos with females $(P<.001)$ and photos with older models to be more realistic than those with younger people $(P<.001)$. In the health care group only, a bilateral pain posture was deemed more realistic than a unilateral pose $(P<.001)$.

Conclusions: Standard images of migraine attacks are considered only slightly or moderately realistic by patients and health care workers. Some characteristics perceived as more realistic such as male sex or older age are in contrast with migraine epidemiology. A more accurate representation of migraine in the media could help to raise awareness for migraine and reduce the associated stigma.

(J Med Internet Res 2021;23(11):e32707) doi: 10.2196/32707

\section{KEYWORDS}

migraine; stigma; mass media; stock photos; advocacy; internet; perception; headache; pain; cross-sectional; survey; stereotype; media; awareness 


\section{Introduction}

Migraine is one of the most common neurological diseases, with a prevalence of $15 \%$ in the general population and rising to over $25 \%$ in women of childbearing age [1-3]. Migraine causes significant limitations in quality of life and functioning [4]. It is the second most common cause of health impairment among nonfatal diseases worldwide, as shown by the years lived with disability measure [4]. Among individuals aged 15 and 49 years, migraine ranks first among the most disabling of diseases [5].

Despite the substantial impact on patients' lives, migraine burden is often underestimated [6]. Many patients feel that their symptoms are dismissed as insignificant [7,8]. Platitudes such as "everybody has headaches" or "it's just stress" are omnipresent in the lives of patients with migraine [7,8]. In a survey by Buse et al [9] , almost half of patients with chronic migraine had the impression that their partner did not believe in their disease. The invisibility of migraine can lead to frustration and stigmatization [7]. Out of fear of being doubted, some patients even hide their symptoms and do not seek treatment, which in turn can have a negative impact on the course of the disease [10,11].

The lack of acceptance of migraine as a real disease has historical roots. Until recently, patients with migraine were portrayed as frail women with weak nerves [12]. Although this representation originates from a cultural background different from the present times, these stereotypes continue to shape the common view of patients with this disease [12].

Currently, digital media, and especially the internet, have become an important source of information on health topics [13]. Portrayals of people with migraine in the media can provide an overview on how society currently sees these patients [14]. Most images resulting from the search term "migraine" show slim and stylish young women holding their temples with an expression of pain on their faces [14]. This trivializing and one-sided portrayal could contribute to the insufficient recognition of migraine-related burden and the growth of social stigma [14].

While this stereotypical representation has already raised concerns among experts [14], no study has assessed how the public perceives such images of migraine. In this study, we aimed to investigate the following questions: (1) do patients with migraine and nonaffected health care workers perceive such photos as realistic? and (2) can patients with migraine relate to these portrayals?

\section{Methods}

\section{Study Design}

This anonymous web-based survey was performed on the REDCap (Research Electronic Data Capture) platform. The link to participate in the survey was distributed among the following two groups:

1. The migraine group: patients at the Headache Center, Charité - Universitätsmedizin Berlin, with a diagnosis of migraine in 2020 per International Classification of Headache Disorders-3 (ICHD-3) criteria [15];

2. The health care group: employees and students at the medical school of Charité - Universitätsmedizin Berlin without migraine.

Patients with migraine received the link to participate via a letter in order to comply with data protection law, while the health care group was invited via email distribution lists and social media groups.

The survey structure is illustrated in Table 1. After the assessment of demographic, occupational, and migraine characteristics, 10 different photos of migraine attacks were presented to the participants on the screen. The participants were instructed to rate on a scale between $0 \%$ and $100 \%$ how much each picture corresponded to a realistic migraine attack. We defined this percentage value as the realism score. Patients with migraine then indicated how closely each image resembled their own migraine experience on the same $0 \%$-to- $100 \%$ scale. This score was named the representation score.

Table 1. Structure of the survey.

\begin{tabular}{ll}
\hline Section & $\begin{array}{l}\text { Description } \\
\text { Study information }\end{array}$ \\
$\begin{array}{l}\text { Written information about the study design and aim, as well as the data protection statement agreement. Subjects } \\
\text { could download the study information to keep for their records. }\end{array}$ \\
In order to access the other questionnaires, participants must confirm that they are $\geq 18$ years of age, that they \\
are voluntarily participating in the survey, and that they agree to the publication of the study results in an \\
anonymous form. Participants could download a consent form to keep for their records.
\end{tabular}


The photos with models were obtained from the stock photo website Adobe Stock (Adobe Inc) [16]. We purchased a commercial license for the use of the 10 photos in the survey. Image selection was based on the following criteria:

- Result of the search term "migraine";

- Sorting by the number of times the photos were downloaded;

- 7 females and 3 males (to match the epidemiological sex distribution of migraine);

- Only 1 person in the photo;

- No black-and-white images;

- No heavy editing or heavy filters and effects;

- Face is visible;

- Only 1 photo of each model;

- Person in the foreground (ie, the background does not take more than half of the image).

\section{Outcomes and Objective}

The primary outcomes of the study were the mean realism score for all photos in both groups and the mean representation score for all photos in patients with migraine.

The secondary outcomes were the mean realism and representation scores for the following categories of photos:

- $\quad$ Photos with female models $(n=7)$;

- $\quad$ Photos with male models $(n=3)$;

- Photos with a unilateral pain posture (ie, models holding one side of the head, $\mathrm{n}=6$ );

- Photos with a bilateral pain posture (ie, models holding both sides of the head, $n=3$ );

- $\quad$ Photos with younger models $(n=5)$;

- Photos with older models $(n=4)$.

The allocation of the photos into each category was agreed upon unanimously by all authors of this paper. To differentiate between younger and older models, we focused on physical characteristics such as face wrinkles or hair color (ie, white or gray).

\section{Statistical Analysis}

The analysis comprises all participants who rated all 10 photos. Employees or students with self-reported migraine were excluded from the health care group.

Demographic and occupational characteristics, as well as realism and representation scores, were summarized with descriptive statistics (absolute frequencies and percentages for categorical variables and mean (SD) values for numerical variables).

We compared the primary and secondary outcome measures between the migraine and health care groups using independent $t$ tests. The realism and representation scores were compared within the migraine group using paired-sample $t$ tests.

We further assessed the correlation of the primary and secondary outcomes with sex, age, ethnicity, highest level of education, and occurrence of migraine among family and friends using Pearson correlation analyses. A 2 -tailed $P$ value $\leq .05$ was considered statistically significant. $P$ values were corrected for multiple comparisons with the Bonferroni method.

\section{Ethics Approval and Consent to Participate}

The study was approved by the ethics committee of the Charité - Universitätsmedizin Berlin (EA1/213/20). Participants were required to provide electronic consent prior to completing the survey.

\section{Results}

\section{Population}

Between October 27, 2020, and January 15, 2021, 367 patients with migraine and 331 Charité employees and medical students completed the survey. The participant selection process is illustrated in Figure 1.

The majority of patients were female ( $\mathrm{n}=318,86.6 \%)$, with an average age of 45.3 (SD 12.7) years. Participants in the health care group were younger (mean 32.1, SD 11.1 years), but their gender and ethnic distribution was similar to that of the migraine group (Table 2). 
Figure 1. Flowchart of participant selection in both groups.

\section{MIGRAINE GROUP}

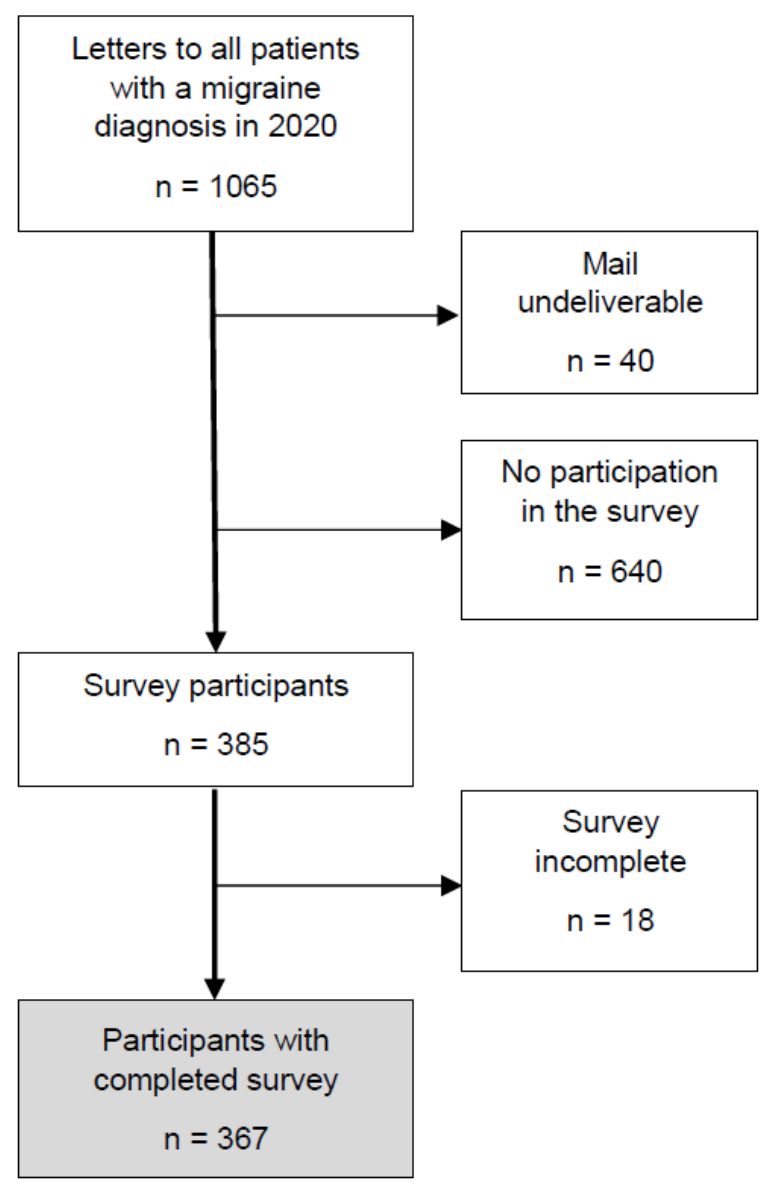

\section{HEALTHCARE GROUP}

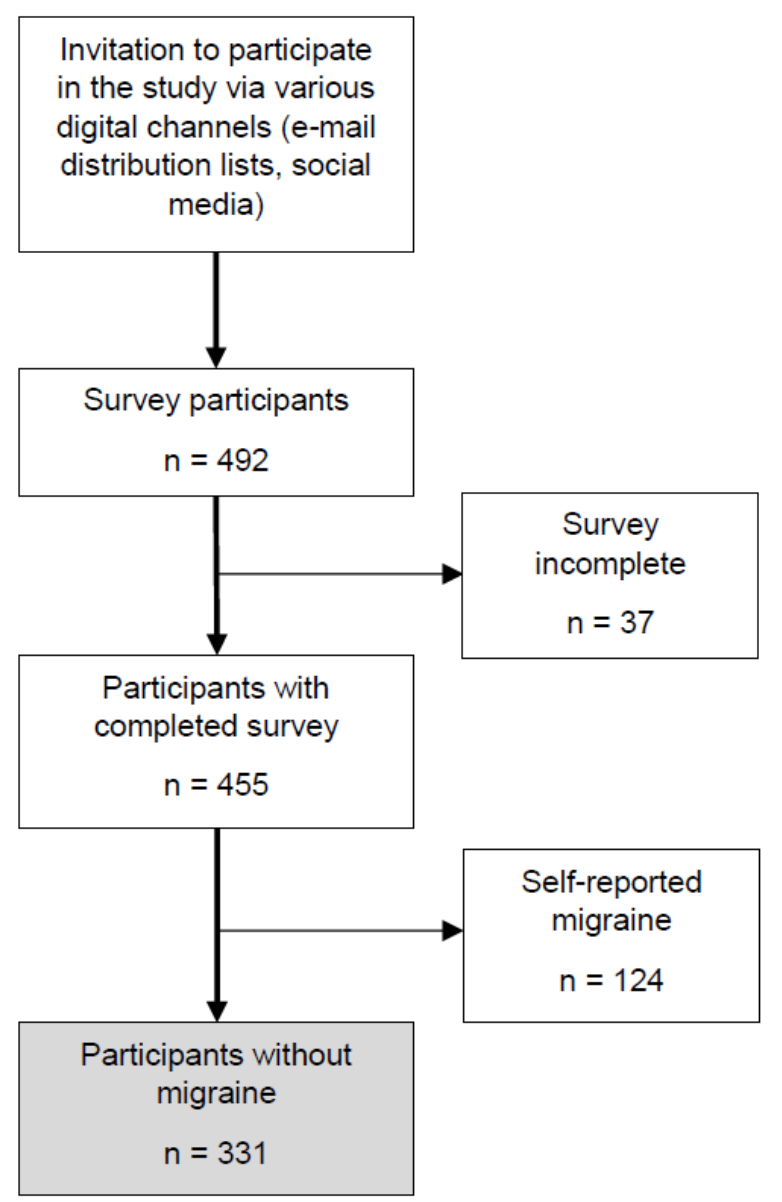


Table 2. Demographic and occupational characteristics of the survey participants.

\begin{tabular}{|c|c|c|}
\hline Characteristic & Migraine group & Health care group \\
\hline Age (years), mean (SD) & $45.3(12.7)$ & $32.1(11.1)$ \\
\hline Female sex, $\mathrm{n}(\%)$ & $318(86.6)$ & 245 (73.9) \\
\hline Northern or Central European descent, n (\%) & $314(85.6)$ & $283(85.6)$ \\
\hline Height (cm), mean (SD) & $168.9(8.1)$ & $171.5(9.7)$ \\
\hline Weight $(\mathrm{kg})$, mean $(\mathrm{SD})$ & $69.4(14.6)$ & $68.3(13.3)$ \\
\hline \multicolumn{3}{|l|}{ Highest level of education, $n(\%)$} \\
\hline University degree & $154(42.1)$ & $118(35.6)$ \\
\hline High school diploma & $63(17.2)$ & $155(46.8)$ \\
\hline Technical baccalaureate & $29(7.9)$ & $8(2.4)$ \\
\hline Apprenticeship & $60(16.4)$ & $20(6.0)$ \\
\hline Intermediate secondary school diploma (Realschulabschluss) & $38(10.4)$ & $13(3.9)$ \\
\hline General secondary school diploma (Hauptschlussabschluss) & $4(1.1)$ & $2(0.6)$ \\
\hline Other & $19(4.9)$ & $15(4.5)$ \\
\hline Close friends or family members with migraine, $\mathrm{n}(\%)$ & $196(53.4)$ & $104(31.4)$ \\
\hline Health care workers' occupation, n (\%) & $-^{\mathrm{a}}$ & $167(50.5)$ \\
\hline Physician & - & $42(25.1)$ \\
\hline Nurse & - & $33(19.8)$ \\
\hline Other medical professionals & - & $27(16.2)$ \\
\hline Other nonmedical professionals & - & $65(38.9)$ \\
\hline Health care students' study subject, n (\%) & - & $164(49.5)$ \\
\hline Human medicine & - & $122(74.4)$ \\
\hline Dentistry & - & $11(6.7)$ \\
\hline Other & - & $31(18.9)$ \\
\hline Regular professional contact with patients with migraine, $\mathrm{n}(\%)$ & - & $68(20.5)$ \\
\hline
\end{tabular}

${ }^{\mathrm{a}}$ Not applicable.

\section{Patients With Migraine}

\section{Realism Scores}

Among patients with migraine, the mean realism score for the 10 photos was $47.8 \%$ (SD 18.3\%). Only 3 out of 10 photos had a mean realism score $>50 \%$. Photos with male models were considered more realistic than photos with female models (mean $51.0 \%$, SD $22.4 \%$ vs mean $47.8 \%$, SD $18.3 \% ; P=.002)$. Patients rated images with older models as more realistic than those with younger models (mean $55.3 \%$, SD $21.0 \%$ vs mean $47.7 \%$, SD $20.1 \%$; $P<.001)$. Photos with unilateral and bilateral pain postures had similar realism scores ( $P>.99$, Figure 2$)$. 
Figure 2. Realism scores of patients with migraine for all photos and different categories. Values are mean (SD), and the asterisk indicates $P<.001$.

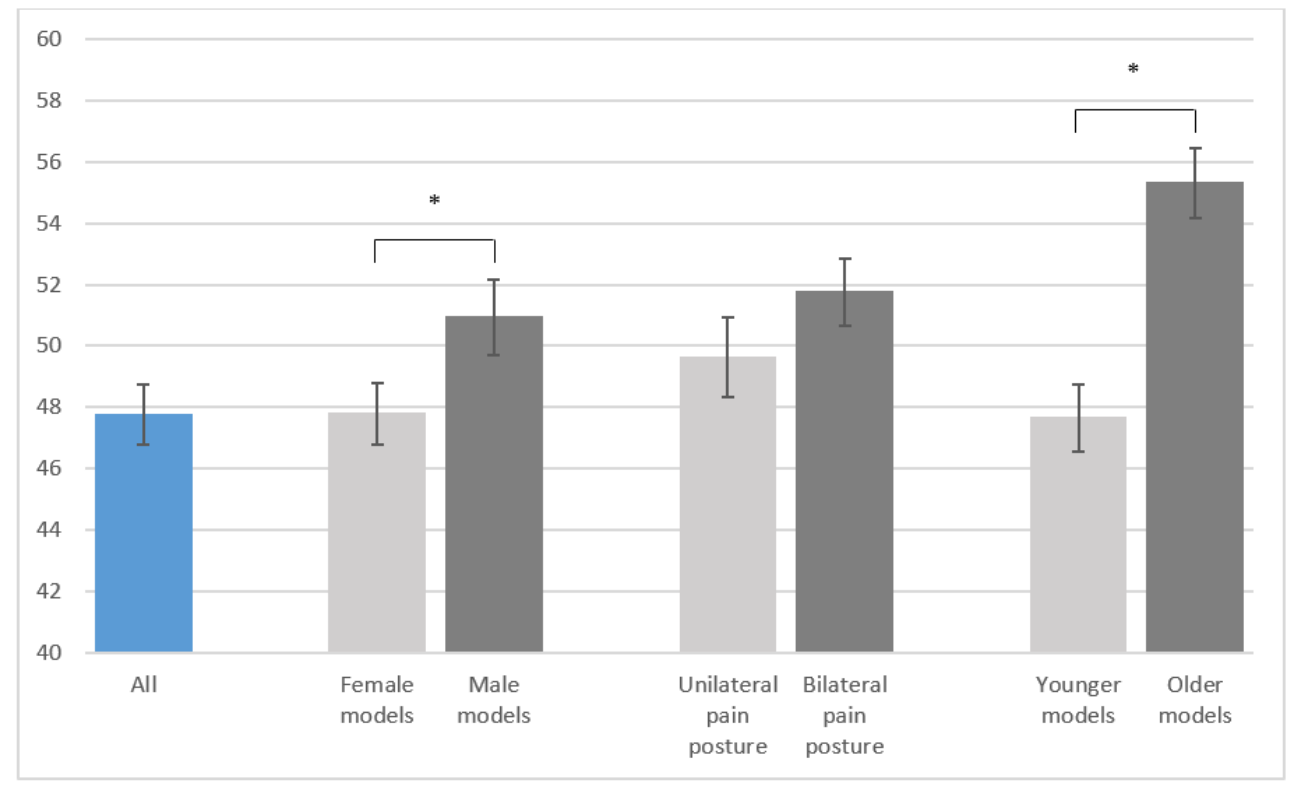

\section{Representation Scores}

When asked how much the images corresponded to their own experience of migraine, the patients answered with a mean representation score of $44.4 \%$ (SD 19.8\%). Photos with older models were considered more representative than photos with younger models (mean $50.3 \%$, SD $22.7 \%$ vs mean $43.2 \%$, SD $21.9 \% ; P<.001)$. The gender of the models did not lead to significant rating differences in the representation score $(P>.99)$. Photos with a unilateral pain posture had similar scores as did photos with a bilateral pain posture $(P>.99$, Figure 3$)$.

Figure 3. Representation scores of patients with migraine for all photos and different categories. Values are mean (SD), and the asterisk indicates $P<.001$.

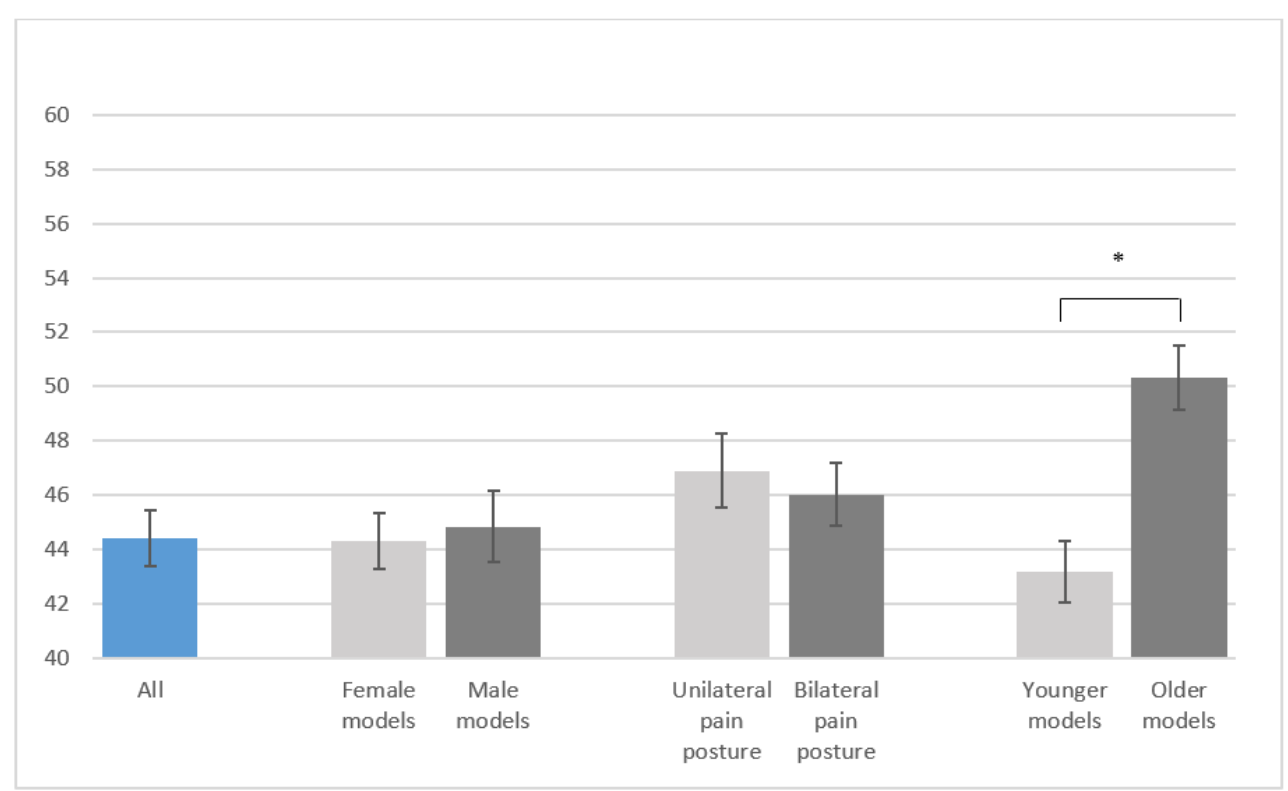

The mean representation score for all photos and in each category was significantly lower than the corresponding realism score $(P<.001$ for all categories).

There was a negative correlation between the highest level of education and both realism and representation scores: the higher the degree, the less realistic $(P<.001, r=0.26)$ and representative $(P<.001, r=0.29)$ the images were rated in all categories. Further analyses revealed a positive correlation between the patients' age and the realism $(P=.047, r=0.11)$ and representation scores $(P=.04, r=0.12)$ of images with older models. There was no correlation with the gender or ethnicity or with the occurrence of migraine among close friends or family members.

\section{Health Care Workers and Students}

\section{Realism Scores}

In the health care group, the 10 photos had a mean realism score of $46.0 \%$ (SD 16.2\%). Similar to the migraine group, only 3 photos were rated as $>50 \%$ for realism. Photos with male models received higher scores than photos with female models (mean $48.6 \%$, SD $20.2 \%$ vs mean $44.9 \%$, SD $16.4 \%$; $P<.001)$. A bilateral pain posture was considered more realistic than a 
unilateral pain posture (mean $50.2 \%$, SD $18.1 \%$ vs mean $41.7 \%$, SD $20.0 \% ; P<.001)$. Photos with older models were rated higher than photos with younger models (mean $52.1 \%$, SD $18.8 \%$ vs mean $43.8 \%$, SD $18.3 \% ; P<.001)$. Figure 4 shows the mean realism scores in the different categories.
There was no correlation to the gender, ethnicity, or age of the participant nor to regular contact with people with migraine $(P>.99)$. Further, we detected a negative correlation with the highest level of education in this group $(P=.004, r=0.16)$.

Figure 4. Realism scores of health care workers and students for all photos and different categories. Values are mean (SD), and the asterisk indicates $P<.001$.

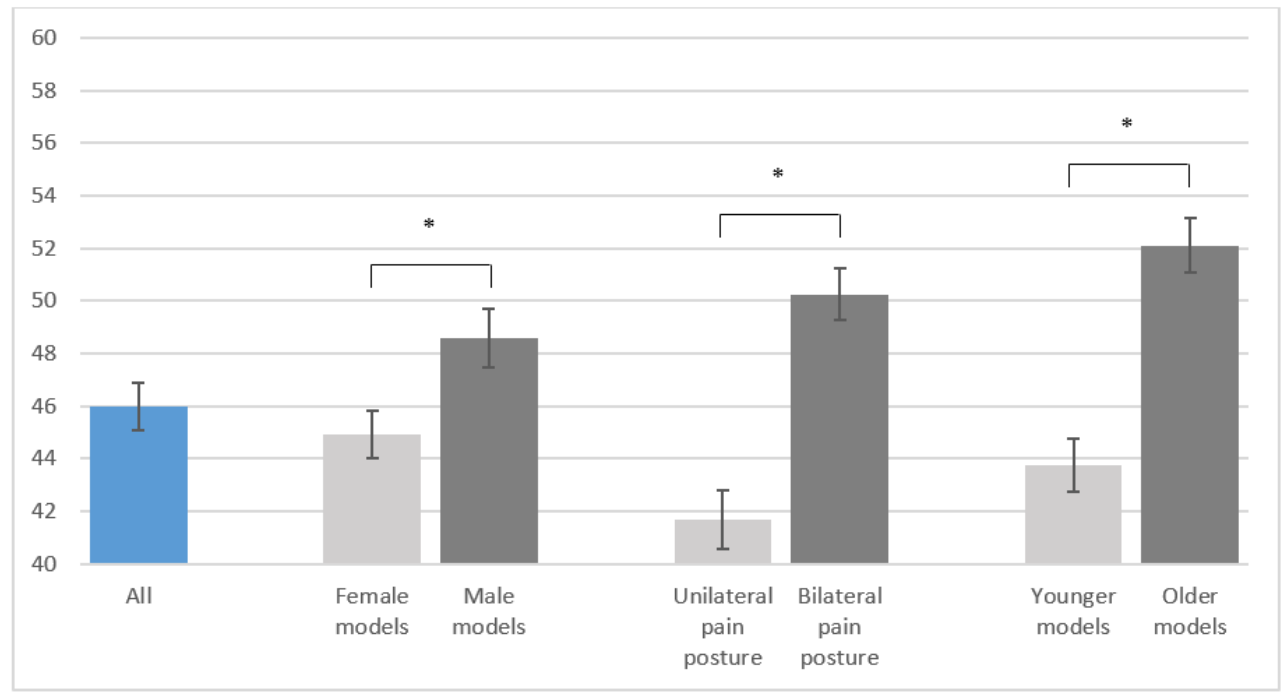

\section{Comparison Between Patients With Migraine and Health Care Workers and Students}

Patients with migraine rated photos with a unilateral pain posture as significantly more realistic than the health care group $(P<.001)$. Overall, the mean realism score for all photos did not differ between the two groups $(P=.23)$. Both groups rated photos with male and older models as more realistic than photos with female and younger models. The mean realism scores for photos with females $(P=.20)$, males $(P>.99)$, younger models $(P=.14)$, and older models $(P=.53)$ were similar between groups.

\section{Discussion}

Patients with migraine and health care workers perceived commonly used stock photos of migraine attacks as slightly or moderately realistic. Patients identified their own migraine experience in these photos to an even lesser degree. Both groups rated photos with male and older models as more realistic than photos with female or younger ones. Among health care workers, a bilateral pain representation was considered more realistic than a unilateral pose.

The differences between media-based representations and the clinical reality have been described by Gvantseladze et al [14]. An analysis of the top 200 images under the search term "migraine" in 2 popular image-searching websites revealed that the majority of these images represented slim White females in a classic pain pose holding one or both temples [14]. The authors argued that this overrepresentation of ectomorph body types and stereotypical pain behaviors may contribute to the social stigmatization of patients with migraine [14]. Our results confirmed that not only experts but also patients doubt the realism of these images. In line with these findings, the Coalition for Headache and Migraine Patients (CHAMP) stated that media representation is often unrealistic and unlikely to display the severity of migraine [17]. The difference between the standard migraine representation and actual migraine behavior may result in the minimization of symptoms and misunderstanding of people living with this disease.

Such an example was illustrated by a social media trend from 2018, in which models and influencers published photos of themselves in the so-called "migraine pose," touching one side of their face [18]. The fashion magazine Elle USA stated that this "flattering" pose "tightens the face, makes your cheekbones look more prominent, and lifts the brows" [18]. The use of the term migraine to name a glamorous pose indicates a lack of public acceptance for migraine as an extremely burdening condition. In line with the CHAMP Image Guide [17], our results support the need for a more accurate portrayal of migraine attacks. A better representation could include migraine symptoms other than headache, such as photophobia, nausea, or cognitive impairment [17]. A more diverse depiction could also help to move away from the classic temporal headache as the only accepted form of migraine pain. For example, a large proportion of migraine patients also have neck pain during attacks [19], which is almost never displayed as a feature of migraine [20].

Hospital employees and medical students shared the patients' critical view of these images. This selected population was able to recognize that this stereotypical representation does not substantially correspond to reality. A more realistic representation of migraine attacks could also have a positive impact on patients' treatment. The process toward effective migraine therapy is often lengthy and difficult [10]. The inaccurate, yet commonly accepted, representation of attacks could lead to a delay in the recognition and diagnosis of migraine, if patients experiencing an attack do not resemble 
these common depictions [10]. Giving visibility to migraine in all its facets could therefore alleviate not only social stigmatization but also the therapeutic burden.

Migraine patients and the health care group rated the laterality of the headache pose differently. A unilateral representation was perceived as more realistic by the patients. Unilaterality is one of the key migraine characteristics according to the ICHD-3 but is not a mandatory criterion for migraine diagnosis [15]. Bilateral pain occurs frequently and, in older patients, it is even more common than strict unilateral attacks [21]. Patients with migraine at a tertiary headache center like ours might be better educated about the typical characteristics of migraine and therefore rate unilaterality as a more realistic migraine feature than the nonaffected group.

Migraine prevalence is 3 times higher in women than in men [3]. However, photos with male models were considered significantly more realistic than those with female models in this analysis, regardless of the rater's gender. This observation fits in well with the literature on gender bias, according to which pain disorders in women are taken less seriously than in men $[22,23]$. Pain expressions of females with chronic pain are underestimated compared to males, and women's pain is considered less severe [24]. In the health care system, women are less likely to receive pain medication than men [25]. On the contrary, psychosocial treatments are more often recommended to female patients experiencing pain [26]. Women with pain diseases are frequently met with skepticism and have to struggle to be believed, which might lead to shame and frustration [27]. If the woman is physically attractive, the credibility of her pain is even lower, which might be applicable to our photo models [28].

Similar considerations may apply to younger patients, especially if female. Young people with pain are often perceived as less ill, based on their healthy physical appearance [29]. This might explain why photos with older models were perceived as more realistic in our survey. This is in contrast with the epidemiology of migraine, which shows a prevalence peak during young adulthood [30].
Finally, our analysis showed that less educated people rated migraine stock images as more realistic than participants with a high level of education. People with a lower education are more likely to be influenced by the media [31,32]. Therefore, it is possible that they are accustomed to this type of migraine representation and do not question its realism. This high receptivity to the media could be useful for educational programs and campaigns to raise awareness for migraine and convey a more accurate and realistic representation.

This is the first study to analyze the perception of commonly used migraine images in a large cohort of patients with migraine and health care workers. Patients with migraine were selected directly from our Headache Center, which ensured a correct diagnosis. Due to data protection regulations, patients could not be contacted by email or telephone. Given that the only possible way to contact the patient was via mail, the response rate of over $30 \%$ is within the normal range of response.

A limitation of the study is that participants completed the survey anonymously online without supervision, which might have a negative impact on data reliability. Some biases may have affected our findings: people with a pre-existing awareness of this topic might have participated to a higher extent in the survey; this applies to younger people who are frequent users of the internet as well. We also divided the photos in six categories, but not all image characteristics were taken into account. For example, the outfit of the models, the surrounding environment, or the severity of the expression of pain were not considered and may represent confounding factors. In addition, only health care workers and students were enrolled in the comparison group, which might not be entirely representative of the general population. The extension of the survey to other members of the public might provide further insights on the perception of migraine.

To conclude, the media representation of migraine was considered at best moderately realistic in our large cohort of patients with migraine and health care workers. The rating of male and older models as more realistic contradicts migraine epidemiology. A more truthful representation of migraine is needed in order to raise awareness of the burden of this disease and to reduce migraine-related social stigma.

\section{Conflicts of Interest}

None declared.

\section{References}

1. GBD 2017 US Neurological Disorders Collaborators, Feigin VL, Vos T, Alahdab F, Amit AML, Bärnighausen TW, et al. Burden of Neurological Disorders Across the US From 1990-2017: A Global Burden of Disease Study. JAMA Neurol 2021 Feb 01;78(2):165-176 [FREE Full text] [doi: 10.1001/jamaneurol.2020.4152] [Medline: 33136137]

2. Bigal ME, Liberman JN, Lipton RB. Age-dependent prevalence and clinical features of migraine. Neurology 2006 Jul 25;67(2):246-251. [doi: 10.1212/01.wnl.0000225186.76323.69] [Medline: 16864816]

3. Allais G, Chiarle G, Sinigaglia S, Airola G, Schiapparelli P, Benedetto C. Gender-related differences in migraine. Neurol Sci 2020 Dec 26;41(Suppl 2):429-436 [FREE Full text] [doi: 10.1007/s10072-020-04643-8] [Medline: 32845494]

4. Stovner LJ, Nichols E, Steiner TJ, Abd-Allah F, Abdelalim A, Al-Raddadi RM, et al. Global, regional, and national burden of migraine and tension-type headache, 1990-2016: a systematic analysis for the Global Burden of Disease Study 2016. Lancet Neurol 2018 Nov;17(11):954-976. [doi: 10.1016/S1474-4422(18)30322-3] 
5. Steiner TJ, Stovner LJ, Vos T, Jensen R, Katsarava Z. Migraine is first cause of disability in under 50s: will health politicians now take notice? J Headache Pain 2018 Feb 21;19(1):17 [FREE Full text] [doi: 10.1186/s10194-018-0846-2] [Medline: 29468450]

6. Katsarava Z, Mania M, Lampl C, Herberhold J, Steiner TJ. Poor medical care for people with migraine in Europe - evidence from the Eurolight study. J Headache Pain 2018 Feb 01;19(1):10 [FREE Full text] [doi: 10.1186/s10194-018-0839-1] [Medline: 29392600]

7. Cottrell C, Drew J, Waller S, Holroyd K, Brose J, O'Donnell F. Perceptions and needs of patients with migraine: a focus group study. Headache 2003 Apr;43(4):428-428. [doi: 10.1046/j.1526-4610.2003.03085 17.x]

8. Pearson C, Swindale R, Keighley P, McKinlay AR, Ridsdale L. Not Just a Headache: Qualitative Study About Web-Based Self-Presentation and Social Media Use by People With Migraine. J Med Internet Res 2019 Jun 19;21(6):e10479 [FREE Full text] [doi: 10.2196/10479] [Medline: 31219049]

9. Buse DC, Scher AI, Dodick DW, Reed ML, Fanning KM, Manack Adams A, et al. Impact of Migraine on the Family: Perspectives of People With Migraine and Their Spouse/Domestic Partner in the CaMEO Study. Mayo Clin Proc 2016 Apr 25;91(5):596-611 [FREE Full text] [doi: 10.1016/j.mayocp.2016.02.013] [Medline: 27132088]

10. Rutberg S, Öhrling K. Migraine--more than a headache: women's experiences of living with migraine. Disabil Rehabil 2012 Oct 10;34(4):329-336 [FREE Full text] [doi: 10.3109/09638288.2011.607211] [Medline: 21981545]

11. Lonardi C. The passing dilemma in socially invisible diseases: narratives on chronic headache. Soc Sci Med 2007 Oct;65(8):1619-1629. [doi: 10.1016/j.socscimed.2007.07.007] [Medline: 17716794]

12. Foxhall K. Wellcome Trust-Funded Monographs and Book Chapters. In: Migraine: A History. Baltimore, MD: Johns Hopkins University Press; 2019.

13. Sassenberg K. Digital media as laypeople's source of information about the environment and health. Bundesgesundheitsblatt Gesundheitsforschung Gesundheitsschutz 2017 Jun;60(6):649-655. [doi: 10.1007/s00103-017-2549-2] [Medline: 28447133]

14. Gvantseladze K, Do TP, Hansen JM, Shapiro RE, Ashina M. The Stereotypical Image of a Person With Migraine According to Mass Media. Headache 2020 Jul 27;60(7):1465-1471. [doi: 10.1111/head.13846] [Medline: 32459017 ]

15. Headache Classification Committee of the International Headache Society (IHS). The International Classification of Headache Disorders, 3rd edition. Cephalalgia 2018 Jan 25;38(1):1-211. [doi: 10.1177/0333102417738202] [Medline: 29368949]

16. Adobe Stock. 2021. URL: https://stock.adobe.com/de/ [accessed 2021-08-29]

17. Guides: Headache and Migraine Disease Language and Image Guide. Coalition for Headache and Migraine Patients (CHAMP). 2018. URL: https://headachemigraine.org/headache-and-migraine-disease-language-and-image-guide/ [accessed 2021-07-24]

18. Rodulfo K. All The Pretty People On Instagram Are Doing The Headache Pose. ELLE. 2018 Jun 26. URL: https://www. elle.com/beauty/a21947206/what-is-headache-pose-instagram/ [accessed 2021-07-24]

19. Ashina S, Bendtsen L, Lyngberg AC, Lipton RB, Hajiyeva N, Jensen R. Prevalence of neck pain in migraine and tension-type headache: a population study. Cephalalgia 2015 Mar 22;35(3):211-219. [doi: 10.1177/0333102414535110] [Medline: 24853166]

20. Rota E, Zucco R, Guerzoni S, Cainazzo MM, Pini LA, Catarci T, et al. Migraine Awareness in Italy and the Myth of "Cervical Arthrosis". Headache 2020 Jan 26;60(1):81-89. [doi: 10.1111/head.13679] [Medline: $\underline{31559636]}$

21. Martins KM, Bordini CA, Bigal ME, Speciali JG. Migraine in the elderly: a comparison with migraine in young adults. Headache 2006 Feb;46(2):312-316. [doi: 10.1111/j.1526-4610.2006.00343.x] [Medline: 16492241]

22. Samulowitz A, Gremyr I, Eriksson E, Hensing G. "Brave Men" and "Emotional Women": A Theory-Guided Literature Review on Gender Bias in Health Care and Gendered Norms towards Patients with Chronic Pain. Pain Res Manag 2018;2018:1-14 [FREE Full text] [doi: 10.1155/2018/6358624] [Medline: 29682130]

23. Hoffmann DE, Tarzian AJ. The girl who cried pain: a bias against women in the treatment of pain. J Law Med Ethics 2001 Jan 01;29(1):13-27. [doi: 10.1111/j.1748-720x.2001.tb00037.x] [Medline: 11521267 ]

24. Zhang L, Losin EAR, Ashar YK, Koban L, Wager TD. Gender Biases in Estimation of Others' Pain. J Pain 2021 Sep;22(9):1048-1059 [FREE Full text] [doi: 10.1016/j.jpain.2021.03.001] [Medline: 33684539]

25. Chen E, Shofer F, Dean A, Hollander J, Baxt W, Robey J, et al. Gender disparity in analgesic treatment of emergency department patients with acute abdominal pain. Acad Emerg Med 2008 May;15(5):414-418 [FREE Full text] [doi: 10.1111/j.1553-2712.2008.00100.x] [Medline: 18439195$]$

26. Hirsh AT, Hollingshead NA, Matthias MS, Bair MJ, Kroenke K. The influence of patient sex, provider sex, and sexist attitudes on pain treatment decisions. J Pain 2014 May;15(5):551-559. [doi: 10.1016/j.jpain.2014.02.003] [Medline: 24576430]

27. Werner A, Isaksen LW, Malterud K. 'I am not the kind of woman who complains of everything': illness stories on self and shame in women with chronic pain. Soc Sci Med 2004 Sep;59(5):1035-1045. [doi: 10.1016/j.socscimed.2003.12.001] [Medline: 15186903$]$

28. LaChapelle DL, Lavoie S, Higgins NC, Hadjistavropoulos T. Attractiveness, diagnostic ambiguity, and disability cues impact perceptions of women with pain. Rehabil Psychol 2014 May;59(2):162-170. [doi: 10.1037/a0035894] [Medline: 24611920] 
29. Werner A, Malterud K. It is hard work behaving as a credible patient: encounters between women with chronic pain and their doctors. Social Science \& Medicine 2003 Oct;57(8):1409-1419. [doi: 10.1016/s0277-9536(02)00520-8]

30. Burch RC, Buse DC, Lipton RB. Migraine: Epidemiology, Burden, and Comorbidity. Neurol Clin 2019 Nov;37(4):631-649. [doi: 10.1016/j.ncl.2019.06.001] [Medline: 31563224]

31. McKay DL, Houser RF, Blumberg JB, Goldberg JP. Nutrition information sources vary with education level in a population of older adults. J Am Diet Assoc 2006 Jul;106(7):1108-1111. [doi: 10.1016/j.jada.2006.04.021] [Medline: 16815128]

32. Jilani HS, Pohlabeln H, Buchecker K, Gwozdz W, De Henauw S, Eiben G, IDEFICS consortium. Association between parental consumer attitudes with their children's sensory taste preferences as well as their food choice. PLoS One 2018 Aug 1;13(8):e0200413 [FREE Full text] [doi: 10.1371/journal.pone.0200413] [Medline: 30067786]

\title{
Abbreviations \\ CHAMP: Coalition for Headache and Migraine Patients \\ ICHD-3: International Classification of Headache Disorders-3 \\ REDCap: Research Electronic Data Capture
}

\author{
Edited by $G$ Eysenbach; submitted 06.08.21; peer-reviewed by P Gazerani; comments to author 27.08.21; revised version received \\ 29.08.21; accepted 20.09.21; published 12.11.21 \\ Please cite as: \\ Raffaelli B, Kull P, Mecklenburg J, Overeem LH, Storch E, Terhart M, Neeb L, Reuter U \\ Patients' and Health Care Workers'Perception of Migraine Images on the Internet: Cross-sectional Survey Study \\ J Med Internet Res 2021;23(11):e32707 \\ URL: https://www.jmir.org/2021/11/e32707 \\ doi: $10.2196 / 32707$ \\ PMID:
}

(CBianca Raffaelli, Pia Kull, Jasper Mecklenburg, Lucas Hendrik Overeem, Elisabeth Storch, Maria Terhart, Lars Neeb, Uwe Reuter. Originally published in the Journal of Medical Internet Research (https://www.jmir.org), 12.11.2021. This is an open-access article distributed under the terms of the Creative Commons Attribution License (https://creativecommons.org/licenses/by/4.0/), which permits unrestricted use, distribution, and reproduction in any medium, provided the original work, first published in the Journal of Medical Internet Research, is properly cited. The complete bibliographic information, a link to the original publication on https://www.jmir.org/, as well as this copyright and license information must be included. 